\title{
Reducing Intestinal Digestion and Absorption of Fat Using a Nature-derived Biopolymer: Interference of Triglyceride Hydrolysis by Nanocellulose
}

\author{
Glen M. DeLoid ${ }^{1,{ }^{*}}$, Ikjot Singh Sohal ${ }^{2}$, Laura R Lorente ${ }^{1}$, Ramon M. Molina ${ }^{1}$, Georgios \\ Pyrgiotakis $^{1}$, Ana Stevanovic ${ }^{1}$, Ruojie Zhang ${ }^{3}$, David Julian McClements ${ }^{3}$, Nicholas K. \\ Geitner $^{4}$, Douglas W. Bousfield ${ }^{5}$, Kee Woei $\mathrm{Ng}^{6}$, Say Chye Joachim Loo ${ }^{6}$, David C. Bell , \\ Joseph Brain ${ }^{1}$, and Philip Demokritou ${ }^{1, *}$ \\ 1. Center for Nanotechnology and Nanotoxicology, Department of Environmental Health, Harvard \\ T. H. Chan School of Public Health, Boston, MA 02115, USA \\ 2. Department of Biomedical Engineering \& Biotechnology, University of Massachusetts Lowell, \\ Lowell, MA, 01854, USA \\ 3. Department of Food Science, University of Massachusetts Amherst, Amherst, MA 01003, USA \\ 4. Department of Civil and Environmental Engineering \& Center for the Environmental Implications \\ of NanoTechnology, Duke University, Durham, NC 27708, USA \\ 5. Department of Chemical and Biological Engineering, University of Maine, Orono, ME 04469, \\ USA \\ 6. School of Materials Science and Engineering, Nanyang Technological University, Singapore \\ 639798 \\ 7. School of Engineering and Applied Sciences, Harvard University, Cambridge, MA, 02138, USA
}

\section{Abstract}

Engineered nanomaterials are increasingly added to foods to improve quality, safety, or nutrition. Here we report the ability of ingested nanocellulose (NC) materials to reduce digestion and absorption of ingested fat. In the small intestinal phase of an acellular simulated gastrointestinal tract, the hydrolysis of free fatty acids (FFA) from triglycerides (TG) in a high-fat food model was reduced by $48.4 \%$ when $\mathrm{NC}$ was added at $0.75 \% \mathrm{w} / \mathrm{w}$ to the food, as quantified by $\mathrm{pH}$ stat titration, and by $40.1 \%$ as assessed by fluorometric FFA assay. Furthermore, translocation of TG and FFA across an in vitro cellular model of the intestinal epithelium was significantly reduced by the presence of $0.75 \% \mathrm{w} / \mathrm{w} \mathrm{NC}$ in the food (TG by $52 \%$, and FFA by $32 \%$ ). Finally, in in vivo experiments, the postprandial rise in serum TG one hour after gavage with the high fat food model was reduced by $36 \%$ when $1.0 \% \mathrm{w} / \mathrm{w} \mathrm{NC}$ was administered with the food. Scanning electron microscopy and molecular dynamics studies suggest two primary mechanisms for this effect: 1)

*corresponding authors, Philip Demokritou,pdemokri@hsph.harvard.edu, Glen M. DeLoid, gdeloid@hsph.harvard.edu. Supporting Information

Morphological characterization of materials, detailed rat serum triglyceride data, TEM and SEM images of nanocellulose and other fibers studies, food model composition, molecular dynamics models images and energy-contacts (docx) 
coalescence of fat droplets on fibrillar NC (CNF) fibers, resulting in a reduction of available surface area for lipase binding, and 2) sequestration of bile salts, causing impaired interfacial displacement of proteins at the lipid droplet surface, and impaired solubilization of lipid digestion products. Together these findings suggest a potential use for NC, as a food additive or supplement, to reduce absorption of ingested fat and thereby assist in weight loss and the management of obesity.

\section{Graphical Abstract}

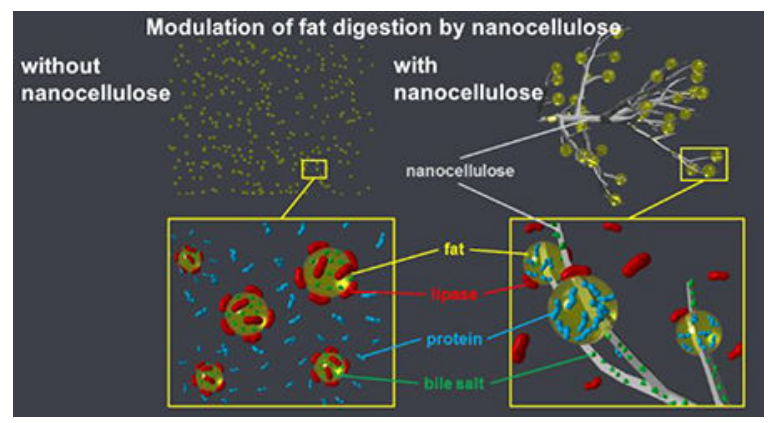

\section{Keywords}

nanocellulose; triglyceride; pancreatic lipase; simulated digestion; bioavailability

Many foods contain nanosize particles, either naturally occurring in the product, ${ }^{1,2}$ generated during processing, or introduced from the environment. ${ }^{2-7}$ Engineered nanomaterials (ENMs) are increasingly added or applied to foods to take advantage of their unique properties to improve quality, safety, or nutrition. ${ }^{8-17}$ Nanocellulose (NC), derived from natural sources, has the potential to be used in food packaging to increase shelf life, or added to the food itself as a source of fiber, to stabilize emulsions and foams, to retain moisture, or to improve appearance and sensory appeal. ${ }^{9,10,18-21}$ The latter effects have been observed at concentrations in food ranging from $\sim 0.2-1.0 \% \mathrm{w} / \mathrm{w} .{ }^{9}$

However, the use of NC in food as a modifier of digestion and absorption of ingested fat has not been explored. Triglycerides, the major constituent of edible fats, cannot be absorbed directly by the GI tract. ${ }^{22,23}$ The fatty acids (FAs) at the 1 and 3 positions of the glycerol backbone must first be removed by pancreatic lipase, primarily occurring in the proximal small intestine. The resulting FAs and monoacylglycerols (MGs) can then be absorbed by small intestinal enterocytes. The absorbed FAs and MGs are then used to regenerate TGs within the enterocytes. TGs regenerated within enterocytes are combined with cholesterol, cholesterol esters and apoprotein b48 to form chylomicrons, which are secreted across the basolateral membrane to enter lacteals. ${ }^{22,23}$ Chylomicrons then move through the lymphatics to the thoracic duct to enter the systemic circulation, where they are taken up by peripheral tissues (primarily adipose and muscle). In addition, some free fatty acids are transported by diffusion through the enterocyte to the submucosal capillaries to directly enter the circulation. ${ }^{22,23}$ 
Our results suggest that $\mathrm{NC}$ derived from a natural wood fiber ${ }^{24}$ using only mechanical means can interact with fatty foods to interfere with the activity of pancreatic lipase, thereby substantially reducing fat digestion and absorption. The effect of $\mathrm{NC}$ on fat digestion was assessed using a high-fat food model (heavy cream) with or without NC by multiple experimental approaches: 1) simulated GIT digestion with $\mathrm{pH}$-Stat titration and fluorometric analysis to measure FFA release during small intestinal digestion; 2) in vitro biokinetics experiments using a triculture model of the small intestinal epithelium to measure translocation of FFA and TG from digestae produced by the GIT simulator; and 3) an in vivo rat gavage with heavy cream with or without $\mathrm{NC}$ and followed by measurement of postprandial serum TG. The results of these studies strongly indicate that $\mathrm{NC}$ reduces TG hydrolysis in the small intestine, and thus lowers fat absorption.

Electron microscopy and molecular dynamic simulations suggest that this effect may involve interactions between NC and TG, and NC and bile salts. Specifically, NC may bridge together multiple fat droplets resulting in coalescence into larger droplets or clusters, thus reducing the available surface area for adsorption of lipase-colipase complexes. In addition, NC may sequester bile salts, which can impair lipolysis in several ways. Bile salts are biosurfactants that play multiple important roles in fat digestion. Interfacial materials (e.g., proteins or surfactants) at the surface of lipid droplets are competitively displaced by bile salts, a process required for optimal adsorption of lipase-colipase complexes and subsequent hydrolysis of TG within the droplets. ${ }^{25}$ Thus, altering the interfacial properties of emulsions to prevent this competitive displacement, or sequestration of bile salts by NC fibers can reduce or delay lipolysis. ${ }^{26-30}$ In addition, bile salts are required for solubilization of the products of lipid digestion (FA and MG) to facilitate their removal from the fat droplet interface. ${ }^{31}$ Failure to remove these products from the lipid droplet surface can impede further digestion. As described below, both fat droplet bridging and coalescence and bile salt sequestration by $\mathrm{NC}$ appear to underlie the observed reduction in TG digestion.

Together the findings reported here suggest that nature-derived NC materials could potentially be used as food additives or supplements to reduce fat absorption to support weight management and improve health.

\section{Results and Discussion}

NC materials used in this study included two fibrillar nanocellulose (CNF) materials of different mean fibril diameters (CNF-50 nm, and CNF-80 nm) and cellulose nanocrystals (CNC-25 nm). As control fibers, micron- scale cellulose fibers (CMF) produced from the same wood fiber, wheat dextrin, and psyllium husk dietary fibers were also included in this study. Characterization data for the nanocellulose materials are summarized in Supplementary Table 1. Although referred to here as CNF-50 nm and CNF-80 nm, the actual mean diameters of these two materials estimated by SEM were 64 and $78 \mathrm{~nm}$, respectively. TEM images of the three nanocellulose materials are shown in Supplementary Figure 1, and demonstrate complex web-like structures for both CNF materials and needle-like structures for CNC-25. SEM images of all fibers studied are shown in Supplementary Figure 2. 
In order to assess the effect of NC and control materials on lipase activity (FFA release and thus fat bioavailability and metabolism), a high-fat model food (heavy cream, purchased from a local supermarket), with or without $0.75 \% \mathrm{w} / \mathrm{w}$ of fiber (or the chemical lipase inhibitor Orlistat at $4.8 \mathrm{mg} / \mathrm{ml}$ as a positive control) with a final fat concentration of $13.3 \%$ w/w, was passed through a 3-phase (mouth, stomach and small intestine) GIT simulator previously described by the authors. ${ }^{32}$ Heavy cream was selected because it is a commonlyused high-fat whole food, and because milkfat is consumed in a wide variety of foods. The $\mathrm{CNF}$ concentration of $0.75 \% \mathrm{w} / \mathrm{w}$ was selected as representing the upper range of nanocellulose employed in potential food applications. ${ }^{9}$ Because hydrolysis of TGs by pancreatic lipase generates free FAs (FFAs), MGs, and hydrogen ions (H+), the amount of titrant $(\mathrm{NaOH})$ that must be added to the small intestine phase to maintain the $\mathrm{pH}$ at 7.0, measured by pH-Stat titration, can be used to determine the extent of TG hydrolysis and the amount of FFA released. Three independent experiments were performed for each fiber and for Orlistat. The extent of TG hydrolysis and FFA release measured by $\mathrm{pH}-\mathrm{Stat}$ titration for each fiber and control is shown in Figure $1 \mathrm{a}-\mathrm{d}$. The lipase inhibitor Orlistat $(4.8 \mathrm{mg} / \mathrm{ml})$ resulted in nearly complete inhibition of TG hydrolysis, as indicated by the low level of $\mathrm{NaOH}$ titrant used and the percentage of total available FFAs released during digestion (91.5\% reduction, $\mathrm{p}<0.0001$ by one-way ANOVA with Dunnett's multiple comparisons test). The three nano-scale NC materials, CNF- $50 \mathrm{~nm}, \mathrm{CNF}-80 \mathrm{~nm}$ and CNC-25 (each at $0.75 \%$ $\mathrm{w} / \mathrm{w}$ ), also caused reductions in $\mathrm{NaOH}$ titrant required to maintain $\mathrm{pH}$ at 7.0, and thus in the percentage of the available fatty acids hydrolyzed. Of these materials, the greatest effect was observed with CNF-50 $\mathrm{nm}$, which reduced fatty acid hydrolysis by $48.4 \%$ compared to control ( $\mathrm{p}<0.0001)$. Reductions were also observed with CNF- $80 \mathrm{~nm}$ ( $40.6 \%$ reduction, $\mathrm{p}<0.0001$ ) and CNC-25 (34.4\% reduction, $\mathrm{p}<0.0001)$. In contrast, $0.75 \% \mathrm{w} / \mathrm{w}$ micron-scale cellulose caused a significant increase in FFA hydrolysis ( $38.4 \%$ increase, $\mathrm{p}<0.0001$ ). Wheat dextrin fibers $(0.75 \% \mathrm{w} / \mathrm{w})$ also resulted in a modest but significant increase in FFA hydrolysis $(15.8 \%, \mathrm{p}<0.05)$. Psyllium husk fibers $(0.75 \% \mathrm{w} / \mathrm{w})$ had no significant effect.

These findings suggest that the interference of TG digestion by cellulose is specific to materials with dimensions in the nano-scale, and likely depends on structural and physical properties unique to the nano-scale of cellulose in CNF and CNC. Differences in effects between NC materials may be related to the available surface area per unit mass, or specific surface area (SSA). The measurement of SSA for these materials is problematic, and approaches for accurate measurement are still under development. However, recentlyreported estimates based on dimensions obtained from electron microscopy, ${ }^{24}$ suggest that SSA is somewhat greater for CNF-50 $\left(34 \mathrm{~m}^{2} / \mathrm{g}\right)$ than for CNF-80 $\left(29 \mathrm{~m}^{2} / \mathrm{g}\right)($ See supplementary Table 1). SSA was not estimated for CMF, however it would be expected to be substantially less than that of either CNF-50 or CNF-80. This would account for a reduced or perhaps absent effect on fat digestion with CMF, but would not account for the observed effect in the opposite direction (increased hydrolysis with CMF). Further studies will be needed to fully elucidate structure activity relationships (fiber size, morphology and surface chemistry vs. effect) in order to further optimize the observed fat digestion modulation behavior of $\mathrm{NC}$ materials. Because it had the greatest effect in the simulated digestion experiments/pH-Stat experiments, CNF-50 was used for all other studies reported here. 
Direct fluorometric assay of FFAs (Figure $1 \mathrm{e}$ ) was also performed on small intestinal phase digesta using the heavy cream food model (13.3\% fat) with and without CNF-50 to corroborate the less-direct $\mathrm{pH}$ Stat digestion results. By this method, small amounts of FFA were present at the start of small intestinal digestion (prior to addition of lipase), with no significant difference between FFA concentrations in digestae $50 \mathrm{~nm} \mathrm{CNF}(620 \pm 590 \mathrm{pM})$ and without CNF $(570 \pm 550 \mathrm{pM})$. Following addition of lipase and two hours of digestion, FFA increased to an average of $20,600 \pm 8000 \mathrm{pM}$ in digesta without CNF, and $11,300 \pm 3100$ $\mathrm{pM}$ in digesta with $50 \mathrm{~nm} \mathrm{CNF}$, representing a statistically significant average reduction of $45 \%$ ( $\mathrm{p}<0.05$ by unpaired $t$ test with Welch's correction, $\mathrm{N}=6$ ), consistent with the simulated digestion/pH stat results presented above.

In order to assess the effect of food matrix and/or fat type, simulated digestions were performed using three additional high-fat food models (mayonnaise, emulsified coconut oil, and emulsified corn oil) and results compared to those for the heavy cream model (Figure 1 f). These food models were selected to include varied amounts of saturated vs. unsaturated fatty acids (Supplementary Figure 3), as well as varied fatty acid chain length profiles (Supplementary Table 3). For each food model, the total initial fat content was adjusted to $13.3 \%$ (to match the \% fat used in the in vitro experiments with the heavy cream model described above). The digestions were performed with or without $0.75 \% \mathrm{w} / \mathrm{w}$ of CNF-50. Three independent experiments were performed for each food model. The results of these experiments were analyzed using an unpaired $t$ test with Welch's correction, and are shown in Figure $1 \mathrm{f}$. The strongest effect was observed with the heavy cream food model (48.4\% reduction, $\mathrm{p}<0.0001)$. Smaller effects were observed for mayonnaise (19\% reduction, $\mathrm{p}<0.001)$, emulsified corn oil (12.8\% reduction, $\mathrm{p}<0.05)$, and emulsified coconut oil $(11.2 \%$ reduction, $\mathrm{p}>0.05)$. These results suggest that fat type and/or food matrix affect the extent of the interference of fat digestion by CNF. The degree of fatty acid saturation, however, did not appear to be a major factor in NC's fat digestion modulating behavior, since the highest fraction of saturated fatty acids among the food models tested occur in heavy cream (65\%) and coconut oil (90\%), for which CNF had the largest and smallest effects, respectively, while mayonnaise and corn oil contain mostly unsaturated fats (Supplementary Figure 3). However, the different lipid phases in the model foods have different fatty acid profiles (chain lengths), which may have impacted the lipid digestion process. Coconut oil contains relatively high levels of medium chain fatty acids (MC-FA), whereas the other fats contain relatively high levels of long chain fatty acids (LC-FA) ${ }^{33}$ After triglyceride hydrolysis, MCFA are released from the oil droplet surfaces more readily than LC-FA. ${ }^{34}$ Indeed, MC-FA formed at oil droplet surfaces by digestion may spontaneously move into the surrounding aqueous phase because of their relatively high hydrophilicity, whereas LC-FA must be incorporated into mixed micelles or sequestered by calcium ions before they can move into the aqueous phase. ${ }^{35}$ If LC-FA are not liberated from the lipid droplet surfaces, then further lipid digestion is inhibited. This effect may account for the experimental observation that the samples containing MC-FA were the least influenced by the presence of nanocellulose. It should be noted that the varied non-fat components, $\mathrm{pHs}$, viscosities, and other properties among the different food models investigated might also affect fat digestion, and may have contributed to the differences observed. Additional systematic studies are required to clarify 
the roles that fatty acid saturation and chain length, and other food matrix properties play in the modulation of fat digestion by NC.

In order to test whether the observed reduction in TG digestion and FFA release during digestion with CNF would affect movement of TG and FFA across the intestinal epithelium (fat absorption), the digestae produced from simulated GIT studies presented above using the heavy cream model with and without $0.75 \%$ w/w CNF-50 was applied to the apical compartment of an in vitro triculture small intestinal epithelial model ${ }^{32}$ (Figure 2 a ). TG and FFA concentrations were then measured in the basolateral compartment after incubation for 2 and 6 hours. Trans-epithelial electrical resistance (TEER) across transwell membranes was also measured and remained constant throughout the experiments $\left(1677 \pm 46 \Omega \mathrm{cm}^{2}\right.$ pre treatment, $1658 \pm 66 \Omega \mathrm{cm}^{2}$ at 2 hours, and $1662 \pm 52 \Omega \mathrm{cm}^{2}$ at 6 hours), indicating that the cell junctions in the monolayers remained intact. Three independent replications were performed. At 2 hours, FFA concentration in the basolateral compartment was reduced by $52 \%$ by the presence of $\mathrm{CNF}$ ( $\mathrm{p}<0.05$ at 2 hours, Figure $2 \mathrm{~b}$ ). At 6 hours, FFA was reduced by an average of $54 \%$ by CNF, but these results did not reach statistical significance. Basolateral TG concentration was reduced by $32 \%$ at 2 hours ( $<<0.05$, Figure $2 \mathrm{c}$ ) and by $35 \%$ at 6 hours (not statistically significant), thus confirming the simulated digestion results described above.

In order to determine whether the effects of NC observed in in vitro simulated GIT studies and the in vitro cell culture model of intestinal epithelium could be observed in vivo animal studies were performed using a rat gavage model. Male Wistar Han rats were given $10 \mathrm{ml} / \mathrm{kg}$ of heavy cream by gavage with or without $1.0 \% \mathrm{w} / \mathrm{w}$ of $\mathrm{CNF}-50$ ( $\mathrm{N}=13$ rats per group). Higher final concentrations of fat $(23.3 \%)$ and CNF $(1.0 \% \mathrm{w} / \mathrm{w})$ were used in these experiments than in in vitro experiments $(13.3 \%$ fat, $0.75 \% \mathrm{CNF})$ to maximize the postprandial rise in serum TG and potential effect of CNF with the limited gavage volume. The $0.75 \%$ and $1.0 \%$ values used in in vitro and in vivo studies, respectively, are both are consistent with percentages of CNF used in potential food applications ${ }^{9}$. Blood was drawn prior to gavage and at 1,2 and 4 hours post gavage for TG analysis. The results, represented as percent change in serum TG from baseline (pre-gavage), are shown in Figure 3. Two animals (one in each group) were excluded as outliers. The data for all individual animals is shown, with outliers indicated, in Supplementary Table 2.

At one hour post gavage, serum TG increased over pre-gavage values by an average of $181 \pm 88 \%$ in rats gavaged with cream only, compared to $115 \pm 45 \%$ in animals gavaged with cream $+\mathrm{CNF}$, representing a statistically significant $36 \%$ reduction in animals that received $\mathrm{CNF}$ ( $\mathrm{p}<0.05$, unpaired t-test). At two hours post gavage, the increase in serum TG (relative to pre-gavage) was $30 \%$ less in rats that received CNF $(119 \pm 68 \%)$ than in rats that received cream only $(172 \pm 100 \%)$. At 4 hours post gavage the change from baseline in serum TG was nearly identical in the two groups $(63 \pm 54 \%$ with cream only vs. $57 \pm 56 \%$ with cream + $\mathrm{CNF})$. Thus, the results of these in vivo studies were consistent with the in vitro digestion and biokinetics results. It should be noted that only male rats were employed in these studies (to minimize differences in weight between animals), and it is possible that results in female rats may differ from those observed in males. Indeed, significant differences in uptake and distribution of long chain n-3 polyunsaturated fatty acids from fish and krill oil have been 
observed between male and female Sprague-Dawley rats. ${ }^{36}$ Likewise, differences might occur between animals of different age and strain, and between different species. Further studies are needed to explore potential differences in the effects of $\mathrm{NC}$ on in vivo fat digestion among these different animal populations.

In order to investigate the possible mechanisms underlying the effect of CNF observed in the above experiments, images of digestae from the simulated digestions were obtained by scanning electron microscopy (SEM). SEM images of digestae at the beginning and end of the small intestinal phase from the digestion of cream (13.3\% fat) with or without $0.75 \%$ CNF-50 are shown in Figure 4. Prior to digestion in cream only samples, fat appears as small droplets extending from a complex structure of fine fibers and thin wavy plaques (Figure $4 \mathrm{a}$ and c). The organization is dramatically different in samples containing CNF (Figure $4 \mathrm{~b}$ and $\mathrm{d}$ ). The CNF in these images appears to be organized with the thicker fibers $(\sim 100-200 \mathrm{~nm})$ forming a honeycomb-like lattice, and the thinner fibers extending from the thicker fibers into the cells of the honeycomb. Fat droplets are seen attached to the thinner CNF fibers. These fat droplets are considerably larger than those observed in samples without CNF. Following digestion, the fat droplets in the cream only samples (Figure $4 \mathrm{e}$ and g) have almost completely disappeared, whereas the fat droplets in samples with CNF remain intact but slightly reduced in size (Figure $4 \mathrm{f}$ and $\mathrm{h}$ ).

The size distributions of fat droplets in the cream only and cream+CNF samples predigestion, and of cream+CNF after digestion, based on image analysis of corresponding SEM images are shown in Figure 5. Prior to digestion, the mean fat droplet diameter was $230 \pm 50 \mathrm{~nm}(\mathrm{~N}=38$ particles analyzed) in cream only samples, and $700 \pm 170 \mathrm{~nm}(\mathrm{~N}=32)$ in cream+CNF samples. Following digestion, in cream only samples, no droplets could be identified, whereas in cream $+\mathrm{CNF}$ samples fat droplets remained and appeared to be as numerous as before digestion, but somewhat smaller in size, $264 \pm 120 \mathrm{~nm}(\mathrm{~N}=55)$. Together these observations suggest that CNF interacts with fat droplets resulting in their coalescence into larger droplets that are less susceptible to digestion by lipase. Thus one explanation for the reduction in TG hydrolysis by lipase observed in the in vitro and in vivo experiments is a reduction in the lipid droplet surface area available for attachment and action of lipase. Furthermore, such entrapment of lipid droplets within the fibrillar structure of the CNF structure may impede access of the lipase to the lipid droplets, further slowing down lipid digestion.

A similar mechanism was observed by Sarkar et al. ${ }^{31,37}$ in studies of the effects of cellulose nanocrystals $(\mathrm{CNC})$ on the rate of digestion of sunflower oil-in-water emulsions. In these studies, emulsions were stabilized by whey protein alone, or whey protein plus $\mathrm{CNC}$. The authors noted significant reduction in TG hydrolysis (by pH Stat) when emulsions were stabilized with both CNC and whey protein as compared with whey protein alone. One of the mechanisms proposed by the authors, and observable by electron microscopy, was the bridging of several droplets by CNCs to form larger droplets with reduced total available surface area for lipase binding and action. CNCs were observed to bind to protein-coated lipid droplets and subsequently bridge multiple droplets together to form larger clusters. In addition, the authors hypothesized that a key mechanism for reduced lipase action was impaired interfacial displacement of proteins by bile salts (required for attachment of lipase 
for digestion), resulting from sequestration of bile salts by the CNCs. Sequestration of bile salts could further slow TG digestion by reducing bile salt-dependent solubilization and removal of free fatty acids and monoacylglycerols from the lipid droplet surfaces.

In order to gain further insights into potential mechanisms, molecular dynamics (MD) simulations were also performed. MD simulations were used to examine interactions between a cellulose nanofiber (Supplementary Figure 4) and a fatty acid, palmitic acid (PA), palmitic triglycerides (PT), a bile salt, glycodeoxycholate (GC) and human pancreatic lipase enzymes (HPL) (Supplementary Figure 5). Palmitic acid simulations included 3 FAs to match the FA content of TG simulations, and TG and GC simulations consisted of a single molecule. Plots of the simulated energies and number of interatomic contacts with the cellulose nanofiber over time are shown in Supplementary Figure 6. Binding energies from MD simulations are shown in Table 1.

PA interacted with cellulose nanofibers weakly (Supplementary Figure 6 a), with a binding energy of $-2.2 \pm 2.3 \mathrm{kcal} / \mathrm{mol}$, which is relatively small compared to the thermal energy of the system ( $\mathrm{RT}=0.6 \mathrm{kcal} / \mathrm{mol}$ ), and was therefore considered nonbinding. PT, however, exhibited substantially stronger $(-4.4 \pm 2.5 \mathrm{kcal} / \mathrm{mol})$ binding energies with cellulose nanofibers (Supplementary Figure $6 \mathrm{~b}$ ). The interactions were also more frequent and longer-lived compared with PA-cellulose nanofiber interactions. This is consistent with the bridging mechanism alluded to above, and the binding of fat droplet clusters to CNF observed by SEM (Figure 4). The bile salt GC also interacted with a modest but statistically significant binding strength $(2.1 \pm 0.7 \mathrm{kcal} / \mathrm{mol})$, safely above the thermal energy of the system, and thus may potentially bind in a dynamic/kinetic fashion, though not as strongly as PT. This is consistent with sequestration of bile salts by CNF, which would impair both interfacial displacement of proteins and solubilization of digestion products. Both depend upon bile salts, and would result in impaired lipolysis, as discussed above. HPL-fiber interactions were considered insignificant due to statistically insignificant interaction energies and short-lived interactions, as well as no change in protein secondary structure (data not shown). Therefore, we concluded that the cellulose nanofiber - PT interactions were the most significant among the tested species, with fiber-GC interactions also possibly playing a role.

Investigating the potential toxicological implications of ingested nanomaterials is of paramount importance. It has been shown in several studies, exposure to ingested inorganic nanoparticles can damage the intestinal microvilli and limit nutrient absorption. ${ }^{38-41}$ Recently published studies of NC toxicity have found no evidence of significant cytotoxicity for CNF materials in several cell line and animal exposure models. ${ }^{42-44}$ Moreover the lack of any change in TEER values during the 6 hour exposure for biokinetics experiments described above, suggest minimal cytotoxicity. Nevertheless, additional studies are needed to more fully evaluate potential toxic effects of ingested CNF. We are currently performing such studies, which will be reported in a future manuscript. 


\section{Conclusions}

We have found, through multiple lines of in vitro and in vivo experiments, that the addition of NC to a high fat food reduces fat digestion and absorption by reducing hydrolysis of triglycerides. From the results of in vitro simulated digestion experiments it appears that this effect is nano-specific. It did not occur when a micron-scale cellulose derived from the same initial fiber was used. The possible mechanisms for this effect appear to include 1) promotion of droplet coalescence and/or flocculation by CNF through a bridging mechanism, resulting in greatly reduced surface area for lipase binding and activity, and 2) sequestration of bile salts by CNF, resulting in impaired interfacial displacement and solubilization of lipid digestion products by bile salts.

Our results suggest that NC materials derived from natural plant fibers using solely mechanical means could potentially be used as either food additives or supplements to provide a non-chemical, safe and effective means of reducing the amount of fat absorbed from food, thereby facilitating weight loss. At $1.0 \% \mathrm{w} / \mathrm{w}$ concentration, the quantity of NC required to achieve this effect in a possible human use would be about $2.3 \mathrm{~g}$ per cup ( 227

g) of high-fat food. Obesity is a worldwide epidemic, and a major healthcare challenge. ${ }^{45-48}$ Diet and exercise, the mainstay of treatment, rarely have lasting effects, owing to persistent physiological changes that increase appetite and promote weight regain. ${ }^{49,50}$ The addition of pharmacological interventions, such as the lipase inhibitor Orlistat, the combination of bupropion and naltrexone, or the glucagon-like peptide-1 (GLP-1) receptor agonist lirglutide, have been shown to produce lasting weight loss. ${ }^{51}$ Although regarded as safe, side effects (e.g. loose, greasy stools with Orlistat and anticholinergic effects with bupropion) may limit compliance and long-term utility.

Additional experiments in animals and humans are needed to further validate the NC fatmodulating findings of this study and to better understand the mechanism(s) underlying the observed effects. We also need to explore potential adverse effects of ingested NC. Based on these initial findings, it appears that NC could provide an additional tool for promoting weight loss in obese populations and for prophylaxis of obesity. In addition to reducing digestion and absorbance of fat in the proximal small intestine, by delivering increased amounts of fat to the distal small intestine, NC could also activate the so-called "ileal brake," whereby fat arriving at the distal ileum triggers the release of satiety hormones (e.g., leptin), reducing appetite and thereby further promoting weight loss. ${ }^{52}$ Moreover, it is likely that the cost of introducing $\mathrm{NC}$ to the market (synthesis, regulatory testing, etc.) would be dramatically less than that for current or future pharmaceutical options.

Finally, in addition to their possible utility in reducing fat absorbance, nature-derived nanomaterials such as $\mathrm{NC}$ might be able to modulate bioavailability and absorbance of other nutrients, or of toxic substances. This could lead to a wide variety of useful applications. Reducing absorption of heavy metals, pesticides, or pharmaceuticals from beverages and foods would be of great value in areas where contamination of water and thus food with such substances is pronounced. The findings of this study open a new scientific arena of engineering naturally derived materials such as $\mathrm{NC}$ and other biopolymers designed to modulate the bioavailability of unwanted substances in the GIT. 


\section{Methods}

\section{Preparation of food model and combination with test fibers or orlistat}

Heavy cream $(33.3 \% \mathrm{w} / \mathrm{w}$ fat), mayonnaise $(76.9 \% \mathrm{w} / \mathrm{w}$ fat) and coconut oil were purchased from a supermarket. Corn oil, sodium caseinate, psyllium husk fiber, wheat dextrin fiber and the chemical lipase inhibitor Orlistat were purchased from Sigma, Inc. (St. Louis, MO).

Details of the methods used to synthesize cellulose materials used in this study are described by the authors in a separate companion manuscript. ${ }^{24}$ Briefly, fibrillar NC materials (CNF-50 nm, CNF-80 nm and CMF) were synthesized using mechanical grinding of a wood fiber, and CNC was synthesized by milling with sulfuric acid. Stock CNF-50 nm, CNF-80 $\mathrm{nm}$ and CMF contained $2.5 \% \mathrm{w} / \mathrm{w}$ cellulose and stock CNC contained $7.0 \% \mathrm{w} / \mathrm{w}$ cellulose. The remainder of each stock material consisted of DI water.

Stock oil in water emulsions (33.3\% w/w fat) with corn oil or coconut oil were created by combining the appropriate amounts of water, sodium caseinate $(0.3 \% \mathrm{w} / \mathrm{w})$ and oil, and homogenizing using a VWR Bio-Gen 200 Homogenizer fitted with a $20 \times 115 \mathrm{~mm}$ sawtooth generator probe (VWR), at high speed for one minute. Stock $33.3 \% \mathrm{w} / \mathrm{w}$ fat mayonnaise emulsion was created by combining mayonnaise $(76.9 \% \mathrm{w} / \mathrm{w}$ fat) with the appropriate amount of water and homogenizing at high speed for one minute.

The final food \pm test fiber or orlistat samples contained $13.3 \% \mathrm{w} / \mathrm{w}$ fat, and either a) $0.75 \%$ $\mathrm{w} / \mathrm{w}$ of one of the fiber materials, b) $4.8 \mathrm{mg} / \mathrm{ml}$ of the lipase inhibitor orlistat $(120 \mathrm{mg}$, the recommended dose for a single meal, in $25 \mathrm{ml}$ total food model), or c) control with no fiber or drug. These samples were created by combining stock food model, water, and either fiber or orlistat, inverting several times to mix, and vortexing the mixture for 10 seconds.

\section{In vitro simulated digestion experiments}

In vitro simulated digestion was performed using a 3-phase (mouth, stomach, small intestine) simulator as previously described. ${ }^{32}$ Briefly, in the mouth phase of the GIT simulator, the nano-enabled food was mixed with a simulated saliva fluid and incubated at $37^{\circ} \mathrm{C}$ for 10 seconds. The resultant mouth digesta was then combined with a simulated gastric fluid and incubated for two hours at $37^{\circ} \mathrm{C}$ on an orbital shaker at $100 \mathrm{rpm}$ to complete the stomach phase. For the small intestinal phase, the stomach digesta was combined with additional salts, bile extract and lipase to simulate intestinal fluid, and incubated at $37^{\circ} \mathrm{C}$ for 2 hours while maintaining a constant $\mathrm{pH}$ of 7.0. $\mathrm{pH}$ was maintained throughout to small intestinal phase using a pH Stat device, and the amount of $\mathrm{NaOH}$ titrant added as a function of time was recorded. FFA at the beginning of the intestinal phase (before addition of lipase) and in the final digesta was measured using a fluorometric assay kit (Cayman Chemical Cat \#700310, assay range 0-250 $\mu \mathrm{M}$ FFA, intra-assay coefficient of variation $5.9 \%$, inter-assay coefficient of variation $5.6 \%$ ).

\section{In vitro biokinetics}

Biokinetics of TG and FFA were assessed using a triculture model of the small intestinal epithelium grown on transwell inserts. The development and methods for generating the 
triculture model were previously described in detail. ${ }^{32}$ Caco-2, HT-29MTX, and Raji B cells were obtained from Sigma, Inc. Caco-2 and HT29-MTX cells were grown in high-glucose DMEM supplemented with $10 \%$ heat-inactivated fetal bovine serum (FBS), $10 \mathrm{mM}$ HEPES buffer, $100 \mathrm{IU} / \mathrm{ml}$ Penicillin, $100 \mathrm{gg} / \mathrm{ml}$ Streptomycin and non-essential amino acids (1/100 dilution of $100 \mathrm{X}$ solution, ThermoFisher). Raji B cells were cultured in RPMI 1640 media supplemented with 10\% FBS, $10 \mathrm{mM}$ HEPES buffer, $100 \mathrm{IU} / \mathrm{ml}$ Penicillin and $100 \mathrm{gg} / \mathrm{ml}$ Streptomycin. Caco-2 and HT-29MTX cells were trypsinized and resuspended in DMEM media at $3 \times 10^{5}$ cells $/ \mathrm{cm}^{3}$, and combined in a ratio of 3:1 (Caco-2:HT29-MTX). $1.5 \mathrm{ml}$ of the cell mixture was seeded in the apical chamber, and $2.5 \mathrm{ml}$ of complete DMEM media was added to the basolateral compartment of a 6 well transwell plate (Corning). Media was changed after four days and subsequently every other day until day 15 . On day 15 and 16 the media in the basolateral compartment was replaced with $2.5 \mathrm{ml}$ of a suspension of Raji B cells at a concentration of $1 \times 10^{6} \mathrm{cells} / \mathrm{ml}$ in 1:1 DMEM: RPMI complete media. Biokinetic experiments were performed on day 17 .

The final digestae from simulated digestions were combined with DMEM media in a ratio of $1: 3$, and $1.5 \mathrm{ml}$ of the mixture was applied to the apical surface of the triculture cells. At 2 and 6 hours after addition of the digesta mixture, FFA in the basolateral fluid was measured using a fluorometric assay kit (Cayman Chemical Cat \#700310), and TG was measured using a colorimetric assay kit (Cayman Chemical, Cat \#10010303, assay range 3.125-200 $\mathrm{mg} / \mathrm{dl} \mathrm{TG}$, lower limit of detection $1.6 \mathrm{mg} / \mathrm{dl} \mathrm{TG}$, intra-assay coefficient of variation $1.34 \%$, inter-assay coefficient of variation 3.17\%). Transepithelial electrical resistance (TEER) was measured using an EVOM2 Epithelial Volt/Ohm Meter with a Chopstick Electrode Set (World Precision Instruments) before addition of digestae and at 2 and 6 hours to ensure maintenance of an intact monolayer throughout the experiments.

\section{In vivo evaluation of effects of CNF on fat absorption using a rat model}

The protocols used in this study were approved by the Harvard Medical Area Animal Care and Use Committee. Male Wistar Han rats (12 weeks old) were obtained from Charles River Laboratories (Wilmington, MA) and were housed in standard micro isolator cages under controlled conditions of temperature, humidity, and light at the Harvard Center for Comparative Medicine. They were fed commercial chow (PicoLab Rodent Diet 5053, Framingham, MA) and were provided with reverse-osmosis purified water ad libitum. The animals were acclimatized in the facility for 7 days before the start of experiments.

Rats were fasted for 24 hours before the experiment. Each rat was anesthetized with isoflurane (Piramal Healthcare, Bethlehem, PA) and weighed. The cream or cream with $\mathrm{CNF}$ test suspension was delivered to the stomach via the esophagus using a 4-inch, 19G gavage needle with $2.25 \mathrm{~mm}$ ball tip ( $\mathrm{n}=13$ rats/group). The volume dose was $10 \mathrm{ml} / \mathrm{kg}$. Animals were returned to cages and were awake for the remainder of the experiment. Venous blood samples (100 ul) were collected via the tail vein before and 1, 2 and 4 hours post-gavage. Blood samples were allowed to clot. Serum was then separated by centrifugation at $5000 \times \mathrm{g}$ for 10 minutes. Serum TG were measured using a colorimetric assay kit (Cayman Chemical, Cat \#10010303). 


\section{Cryo-scanning electron microscopy (Cryo-SEM)}

Liquid digesta samples from simulated GIT digestion were drop casted on a copper substrate and subsequently flash-frozen in liquid nitrogen. The frozen samples were then mounted on a stainless steel stage under liquid nitrogen, collected with a pre-cooled transferring $\operatorname{rod}(\mathrm{T}=$ $-150^{\circ} \mathrm{C}$ ) and transferred into a high vacuum chamber (Leica, Baltec Carbon Coater). Excess ice was cut mechanically using a cold blade $\left(\mathrm{T}=-177^{\circ} \mathrm{C}\right)$ to provide better exposure of samples to the electron beam. Ice was then finely sublimated by annealing samples from $-1{ }^{\circ} \mathrm{C}$ to $-100{ }^{\circ} \mathrm{C}$ for $10 \mathrm{~min}$. to further expose the features of interest. Upon annealing, samples were cooled bac to $-150{ }^{\circ} \mathrm{C}$ and then sputter-coated by Pt-Pd alloy depositing $\sim 10$ $\mathrm{nm}$ layer to increase the conductivity for electron beam imaging. Prepared samples were transferred under vacuum to the Cryo-SEM where they were mounted on a liquid-nitrogen cooled stage. Images were acquired using a Cryo-SEM (Zeiss-NVision 40) operating at $-150{ }^{\circ} \mathrm{C}$, with a $3 \mathrm{keV}$ electron energy beam and two detectors: secondary electron and Inlens. Image analysis to obtain fat droplet size distribution histograms and droplet diameter means and standard deviations was performed using Origin 2018 software (OriginLab, Inc.).

\section{Discrete molecular dynamics (DMD) Simulations}

Systems were modeled in all-atom DMD simulations with the MedusaScore force field, ${ }^{53}$ which was previously parameterized on a large set of ligands and is transferrable to different molecular systems. Simulations were carried out in a simulation box size of $300 \AA^{3}$ with periodic boundary conditions. Unless otherwise noted, the temperature for each simulation was $0.603 \mathrm{kcal} /\left(\mathrm{mol} \cdot \mathrm{k}_{\mathrm{B}}\right)$, which corresponds approximately to $37^{\circ} \mathrm{C}$. Constant temperature was maintained using the Anderson thermostat. ${ }^{54}$ After initialization, energy minimization was carried out for 1000 time steps of approximately $500 \mathrm{ps}$ each. Production simulations were subsequently run for 500,000 time steps (approximately $25 \mathrm{ns).} \mathrm{Time-dependent} \mathrm{data}$ was tjem extracted over the entire simulation to estimate the energy of binding $(\Delta E)$ and the number of atomic contacts between simulation constituents. Two atoms were defined as being in contact when within $6.5 \AA$ of each other. All simulations were carried out on the Duke Compute Cluster, housed at Duke University. Each simulation was carried out on a single CPU core and completion times ranged from 3 to 130 hours.

The initial structure of human pancreatic lipase was obtained from the Protein Data Bank (PDB, entry 1eth). ${ }^{55}$ All other molecules were constructed using the Avogadro molecular builder (v 1.1.1), ${ }^{56}$ and included all heavy atoms and hydrogens. For those species with potentially charged moieties, a $\mathrm{pH}$ of 7.4 was assumed and sodium ions were incorporated into the simulation to balance the system net charge.

To estimate the binding energies, potential energy $(E)$ of the unbound system was obtained by calculating the mean and standard deviation values for all time points where the constituents were far from each other. Two molecules were considered bound when the value of interatomic contacts was non-zero. During all such time points, the mean and standard deviations of the potential energy of the bound state were again calculated. These two mean values were then used to calculate the $\Delta \mathrm{E}$ of binding. 
A model cellulose nanofiber was formed from a set of 9 identical cellulose polymers. Each polymer was constructed from 40 repeating Glucose units. Because cellulose fibers are constructed primarily through a hydrogen bond network, ${ }^{57}$ such a network was first allowed to self-assemble by performing a series of temperature-cycle simulations. The result was a self-assembled cellulose nanofiber $19 \mathrm{~nm}$ long, approximately $4.5 \mathrm{~nm}$ high and $3.5 \mathrm{~nm}$ wide with a robust hydrogen bond network. The fiber was held static in subsequent simulations to preserve this self-assembled state.

\section{Statistical analysis}

Statistical analysis of data was performed using Prism 7.03 software (GraphPad Software, Inc.). Results of $\mathrm{pH}$ stat digestions of different fibers and controls were analyzed by one-way ANOVA with Dunnett's multiple comparisons test. Analysis of $\mathrm{pH}$ stat digestion results for different food models was performed using an unpaired $t$ test with Welch's correction. Analysis of results from fluorometric assay of FFA in digesta and of FFA and TG from biokinetics experiments were analyzed using a ratio paired $t$ test. Analysis of serum TG from in vivo gavage experiments was performed using an unpaired $t$ test. For molecular dynamics studies, a t test was used to determine whether 2 interactions were statistically significantly different from each other, with $\mathrm{p}<0.05$ threshold. Similarly, binding energies plus or minus standard deviations were compared using t test to unbound energy plus or minus standard deviations to determine whether binding was statistically significant.

\section{Supplementary Material}

Refer to Web version on PubMed Central for supplementary material.

\section{Acknowledgements}

Support for the research reported, including assets and resources required for designing and performing experiments, data analysis, and interpretation, was provided by the Nanyang Technological University-Harvard T. H. Chan School of Public Health Initiative for Sustainable Nanotechnology. Research reported in this publication was supported by the HSPH Center for Nanotechnology and Nanotoxicology and National Institute of Environmental Health Sciences of the National Institutes of Health under Award Number (NIH grant \# U24ES026946) as part of the Nanotechnology Health Implications Research (NHIR) Consortium, and the NIEHS Environmental Health Center Grant (\#ES-000002). The content is solely the responsibility of the authors and does not necessarily represent the official views of the National Institutes of Health.

The engineered nanomaterials used in the research presented in this publication were developed, characterized, and provided by the Engineered Nanomaterials Resource and Coordination Core established at Harvard T. H. Chan School of Public Health (NIH grant \# U24ES026946) as part of the Nanotechnology Health Implications Research Consortium.

\section{References}

(1). Servin AD; White JC Nanotechnology in Agriculture: Next Steps for Understanding Engineered Nanoparticle Exposure and Risk. NanoImpact 2016, 1, 9-12.

(2). Schoepf JJ; Bi Y; Kidd J; Herckes P; Hristovski K; Westerhoff P Detection and Dissolution of Needle-like Hydroxyapatite Nanomaterials in Infant Formula. NanoImpact 2017, 5, 22-28.

(3). McClements DJ; DeLoid G; Pyrgiotakis G; Shatkin JA; Xiao H; Demokritou P The Role of the Food Matrix and Gastrointestinal Tract in the Assessment of Biological Properties of Ingested Engineered Nanomaterials (IENMs): State of the Science and Knowledge Gaps. NanoImpact 2016, 3, 47-57. [PubMed: 29568810] 
(4). Bellmann S; Carlander D; Fasano A; Momcilovic D; Scimeca JA; Waldman WJ; Gombau L; Tsytsikova L; Canady R; Pereira DIA; et al. Mammalian Gastrointestinal Tract Parameters Modulating the Integrity, Surface Properties, and Absorption of Food-Relevant Nanomaterials. Wiley Interdiscip. Rev. Nanomed. Nanobiotechnol 2015, 7 (5), 609-622. [PubMed: 25641962]

(5). Szakal C; Roberts SM; Westerhoff P; Bartholomaeus A; Buck N; Illuminato I; Canady R; Rogers M Measurement of Nanomaterials in Foods: Integrative Consideration of Challenges and Future Prospects. ACS Nano 2014, 8 (4), 3128-3135. [PubMed: 24673283]

(6). Yada RY; Buck N; Canady R; DeMerlis C; Duncan T; Janer G; Juneja L; Lin M; McClements DJ; Noonan G; et al. Engineered Nanoscale Food Ingredients: Evaluation of Current Knowledge on Material Characteristics Relevant to Uptake from the Gastrointestinal Tract. Compr. Rev. Food Sci. Food Saf 2014, 13 (4), 730-744.

(7). Eleftheriadou M; Pyrgiotakis G; Demokritou P Nanotechnology to the Rescue: Using NanoEnabled Approaches in Microbiological Food Safety and Quality. Curr. Opin. Biotechnol 2016, 44, 87-93. [PubMed: 27992831]

(8). Wang H; Du L-J; Song Z-M; Chen X-X Progress in the Characterization and Safety Evaluation of Engineered Inorganic Nanomaterials in Food. Nanomedicine (Lond). 2013, 8 (12), 2007-2025. [PubMed: 24279490]

(9). Strom G; OHgren C; Ankerfors M Nanocellulose as an Additive in Foodstuff; Stockholm, Sweden, 2013.

(10). Shahabi-Ghahfarrokhi I; Khodaiyan F; Mousavi M; Yousefi H Green Bionanocomposite Based on Kefiran and Cellulose Nanocrystals Produced from Beer Industrial Residues. Int. J. Biol. Macromol 2015, 77, 85-91. [PubMed: 25797402]

(11). Peters RJB; van Bemmel G; Herrera-Rivera Z; Helsper HPFG; Marvin HJP; Weigel S; Tromp PC; Oomen AG; Rietveld AG; Bouwmeester H Characterization of Titanium Dioxide Nanoparticles in Food Products: Analytical Methods To Define Nanoparticles. J. Agric. Food Chem 2014, 62 (27), 6285-6293. [PubMed: 24933406]

(12). Lim J-H; Sisco P; Mudalige TK; Sánchez-Pomales G; Howard PC; Linder SW Detection and Characterization of $\mathrm{SiO} 2$ and $\mathrm{TiO} 2$ Nanostructures in Dietary Supplements. J. Agric. Food Chem 2015, 63 (12), 3144-3152. [PubMed: 25738207]

(13). Chen H; Seiber JN; Hotze M ACS Select on Nanotechnology in Food and Agriculture: A Perspective on Implications and Applications. J. Agric. Food Chem 2014, 62 (6), 1209-1212. [PubMed: 24479582]

(14). Athinarayanan J; Periasamy VS; Alsaif MA; Al-Warthan AA; Alshatwi AA Presence of Nanosilica (E551) in Commercial Food Products: TNF-Mediated Oxidative Stress and Altered Cell Cycle Progression in Human Lung Fibroblast Cells. Cell Biol. Toxicol 2014, 30 (2), 89-100. [PubMed: 24526451]

(15). Athinarayanan J; Alshatwi AA; Periasamy VS; Al-Warthan AA Identification of Nanoscale Ingredients in Commercial Food Products and Their Induction of Mitochondrially Mediated Cytotoxic Effects on Human Mesenchymal Stem Cells. J. Food Sci. 2015, 80 (2), N459-64. [PubMed: 25586546]

(16). Pyrgiotakis G; Vasanthakumar A; Gao Y; Eleftheriadou M; Toledo E; DeAraujo A; McDevitt J; Han T; Mainelis G; Mitchell R; et al. Inactivation of Foodborne Microorganisms Using Engineered Water Nanostructures (EWNS). Environ. Sci. Technol 2015, 49 (6), 3737-3745. [PubMed: 25695127]

(17). Pyrgiotakis G; Vedantam P; Cirenza C; McDevitt J; Eleftheriadou M; Leonard SS; Demokritou P Optimization of a Nanotechnology Based Antimicrobial Platform for Food Safety Applications Using Engineered Water Nanostructures (EWNS). Sci. Rep 2016, 6, 21073. [PubMed: 26875817]

(18). Khan RA; Salmieri S; Dussault D; Uribe-Calderon J; Kamal MR; Safrany A; Lacroix M Production and Properties of Nanocellulose-Reinforced Methylcellulose-Based Biodegradable Films. J. Agric. Food Chem 2010, 58 (13), 7878-7885. [PubMed: 20545366]

(19). Mariano M; El Kissi N; Dufresne A Cellulose Nanocrystals and Related Nanocomposites: Review of Some Properties and Challenges. J. Polym. Sci. Part B Polym. Phys 2014, 52 (12), 791-806. 
(20). Nair SS; Zhu J; Deng Y; Ragauskas AJ High Performance Green Barriers Based on Nanocellulose. Sustain. Chem. Process 2014, 2 (1), 23.

(21). Ong KJ; Shatkin JA; Nelson K; Ede JD; Tetsina T Establishing the Safety of Novel Bio-Based Cellulose Nanomaterials for Commercialization. NanoImpact 2017, 6, 19-29.

(22). Costanzo LS Physiology, 5th ed.; Saunders Elservier: Philadelphia, PA, 2014.

(23). Nelson DL; Cox MM Lehninger Principles of Biochemistry, 7th ed.; Freeman WH, 2017.

(24). Pyrgiotakis G; Luu W; Zhang Z; Vase N; DeLoid G; Rubio L; Bell D; Bousfield D; Demokritou P Development of High Throughput, High Precision Synthesis Platforms and Characterization Methodologies for Toxicological Studies of Nanocellulose. Cellulose 2018, 25 (4), 2303-2319.

(25). Maldonado-Valderrama J; Wilde P; Macierzanka A; Mackie A The Role of Bile Salts in Digestion. Adv. Colloid Interface Sci. 2011, 165 (1), 36-46. [PubMed: 21236400]

(26). Corstens MN; Berton-Carabin CC; Kester A; Fokkink R; van den Broek JM; de Vries R; Troost FJ; Masclee AAM; Schroen K Destabilization of Multilayered Interfaces in Digestive Conditions Limits Their Ability to Prevent Lipolysis in Emulsions. Food Struct. 2017, 12, 54-63.

(27). Golding M; Wooster TJ The Influence of Emulsion Structure and Stability on Lipid Digestion. Curr. Opin. Colloid Interface Sci 2010, 15 (1-2), 90-101.

(28). Sandra S; Decker EA; McClements DJ Effect of Interfacial Protein Cross-Linking on the in Vitro Digestibility of Emulsified Corn Oil by Pancreatic Lipase. J. Agric. Food Chem 2008, 56 (16), 7488-7494. [PubMed: 18605732]

(29). Sarkar A; Horne DS; Singh H Pancreatin-Induced Coalescence of Oil-in-Water Emulsions in an in Vitro Duodenal Model. Int. Dairy J 2010, 20 (9), 589-597.

(30). Sarkar A; Murray B; Holmes M; Ettelaie R; Abdalla A; Yang X In Vitro Digestion of Pickering Emulsions Stabilized by Soft Whey Protein Microgel Particles: Influence of Thermal Treatment. Soft Matter 2016, 12 (15), 3558-3569. [PubMed: 26959339]

(31). Sarkar A; Li H; Cray D; Boxall S Composite Whey Protein-cellulose Nanocrystals at Oil-Water Interface: Towards Delaying Lipid Digestion. Food Hydrocoll. 2018, 77, 436-444.

(32). DeLoid GM; Wang Y; Kapronezai K; Lorente LR; Zhang R; Pyrgiotakis G; Konduru NV; Ericsson M; White JC; De La Torre-Roche R; et al. An Integrated Methodology for Assessing the Impact of Food Matrix and Gastrointestinal Effects on the Biokinetics and Cellular Toxicity of Ingested Engineered Nanomaterials. Part. Fibre Toxicol 2017, 14 (1), 40. [PubMed: 29029643]

(33). Akoh CC; Min DB Food Lipids: Chemistry, Nutrition and Biotechnology, 3rd ed.; CRC Press: Boca Raton, FL, 2008.

(34). Williams HD; Trevaskis NL; Charman SA; Shanker RM; Charman WN; Pouton CW; Porter CJH Strategies to Address Low Drug Solubility in Discovery and Development. Pharmacol. Rev 2013, 65 (1), 315-499. [PubMed: 23383426]

(35). Devraj R; Williams HD; Warren DB; Mullertz A; Porter CJH; Pouton CW In Vitro Digestion Testing of Lipid-Based Delivery Systems: Calcium Ions Combine with Fatty Acids Liberated from Triglyceride Rich Lipid Solutions to Form Soaps and Reduce the Solubilization Capacity of Colloidal Digestion Products. Int. J. Pharm 2013, 441 (1-2), 323-333. [PubMed: 23178598]

(36). Ghasemifard S; Hermon K; Turchini GM; Sinclair AJ Metabolic Fate (Absorption, B-Oxidation and Deposition) of Long-Chain n-3 Fatty Acids Is Affected by Sex and by the Oil Source (Krill Oil or Fish Oil) in the Rat. Br. J. Nutr 2015, 114 (05), 684-692. [PubMed: 26234617]

(37). Sarkar A; Zhang S; Murray B; Russell JA; Boxal S Modulating in Vitro Gastric Digestion of Emulsions Using Composite Whey Protein-Cellulose Nanocrystal Interfaces. Colloids Surfaces B Biointerfaces 2017, 158, 137-146. [PubMed: 28688363]

(38). McClements DJ; DeLoid G; Pyrgiotakis G; Shatkin JA; Xiao H; Demokritou P The Role of the Food Matrix and Gastrointestinal Tract in the Assessment of Biological Properties of Ingested Engineered Nanomaterials (IENMs): State of the Science and Knowledge Gaps. NanoImpact 2016, 3-4.

(39). Koeneman BA; Zhang Y; Westerhoff P; Chen Y; Crittenden JC; Capco DG Toxicity and Cellular Responses of Intestinal Cells Exposed to Titanium Dioxide. Cell Biol. Toxicol 2010, 26 (3), 225238. [PubMed: 19618281] 
(40). Guo Z; Martucci NJ; Moreno-Olivas F; Tako E; Mahler GJ Titanium Dioxide Nanoparticle Ingestion Alters Nutrient Absorption in an in Vitro Model of the Small Intestine. NanoImpact 2017, 5, 70-82. [PubMed: 28944308]

(41). Setyawati MI; Sevencan C; Bay B-H; Xie J; Zhang Y; Demokritou P; Leong DT Nano-TiO2 Drives Epithelial -Mesenchymal Transition in Intestinal Epithelial Cancer Cells. Small 2018, In press.

(42). Bhattacharya K; Kilî G; Costa PM; Fadeel B Cytotoxicity Screening and Cytokine Profiling of Nineteen Nanomaterials Enables Hazard Ranking and Grouping Based on Inflammogenic Potential. Nanotoxicology 2017, 11 (6), 809-826. [PubMed: 28816564]

(43). Menas AL; Yanamala N; Farcas MT; Russo M; Friend S; Fournier PM; Star A; Iavicoli I; Shurin GV; Vogel UB; et al. Fibrillar vs Crystalline Nanocellulose Pulmonary Epithelial Cell Responses: Cytotoxicity or Inflammation? Chemosphere 2017, 171, 671-680. [PubMed: 28061425]

(44). Endes C; Camarero-Espinosa S; Mueller S; Foster EJ; Petri-Fink A; Rothen-Rutishauser B; Weder C; Clift MJD A Critical Review of the Current Knowledge Regarding the Biological Impact of Nanocellulose. J. Nanobiotechnology 2016, 14 (1), 78. [PubMed: 27903280]

(45). NCD Risk Factor Collaboration (NCD-RisC). Trends in Adult Body-Mass Index in 200 Countries from 1975 to 2014: A Pooled Analysis of 1698 Population-Based Measurement Studies with 192 Million Participants. Lancet (London, England) 2016, 387 (10026), 1377-1396.

(46). Bray GA; Kim KK; Wilding JPH; World Obesity Federation. Obesity: A Chronic Relapsing Progressive Disease Process. A Position Statement of the World Obesity Federation. Obes. Rev 2017, 18 (7), 715-723. [PubMed: 28489290]

(47). Withrow D; Alter DA The Economic Burden of Obesity Worldwide: A Systematic Review of the Direct Costs of Obesity. Obes. Rev 2011, 12 (2), 131-141. [PubMed: 20122135]

(48). Wang YC; McPherson K; Marsh T; Gortmaker SL; Brown M Health and Economic Burden of the Projected Obesity Trends in the USA and the UK. Lancet 2011, 378 (9793), 815-825. [PubMed: 21872750]

(49). Sumithran P; Prendergast LA; Delbridge E; Purcell K; Shulkes A; Kriketos A; Proietto J LongTerm Persistence of Hormonal Adaptations to Weight Loss. N. Engl. J. Med 2011, 365 (17), 1597-1604. [PubMed: 22029981]

(50). Polidori D; Sanghvi A; Seeley RJ; Hall KD How Strongly Does Appetite Counter Weight Loss? Quantification of the Feedback Control of Human Energy Intake. Obesity (Silver Spring). 2016, 24 (11), 2289-2295. [PubMed: 27804272]

(51). Bessesen DH; Van Gaal LF Progress and Challenges in Anti-Obesity Pharmacotherapy. Lancet Diabetes Endocrinol. 2017.

(52). Maljaars PWJ; Peters HPF; Mela DJ; Masclee AAM Ileal Brake: A Sensible Food Target for Appetite Control. A Review. Physiol. Behav 2008, 95 (3), 271-281. [PubMed: 18692080]

(53). Yin S; Biedermannova L; Vondrasek J; Dokholyan NV MedusaScore: An Accurate Force FieldBased Scoring Function for Virtual Drug Screening. J. Chem. Inf. Model 2008, 48 (8), 16561662. [PubMed: 18672869]

(54). Andersen HC Molecular Dynamics Simulations at Constant Pressure and/or Temperature. J. Chem. Phys 1980, 72 (4), 2384-2393.

(55). Hermoso J; Pignol D; Kerfelec B; Crenon I; Chapus C; Fontecilla-Camps JC Lipase Activation by Nonionic Detergents. The Crystal Structure of the Porcine Lipase-Colipase-Tetraethylene Glycol Monooctyl Ether Complex. J. Biol. Chem 1996, 271 (30), 18007-18016. [PubMed: 8663362]

(56). Hanwell MD; Curtis DE; Lonie DC; Vandermeersch T; Zurek E; Hutchison GR Avogadro: An Advanced Semantic Chemical Editor, Visualization, and Analysis Platform. J. Cheminform 2012, 4 (1), 17. [PubMed: 22889332]

(57). Saitoh L; Ohno H; Matsuo S No TitleStructure and Mechanical Behavior of Cellulose Nanofiber and Micro-Fibrils by Molecular Dynamics Simulation. Soft Nanosci. Lett 2013, 3 (3), 58-67. 
a
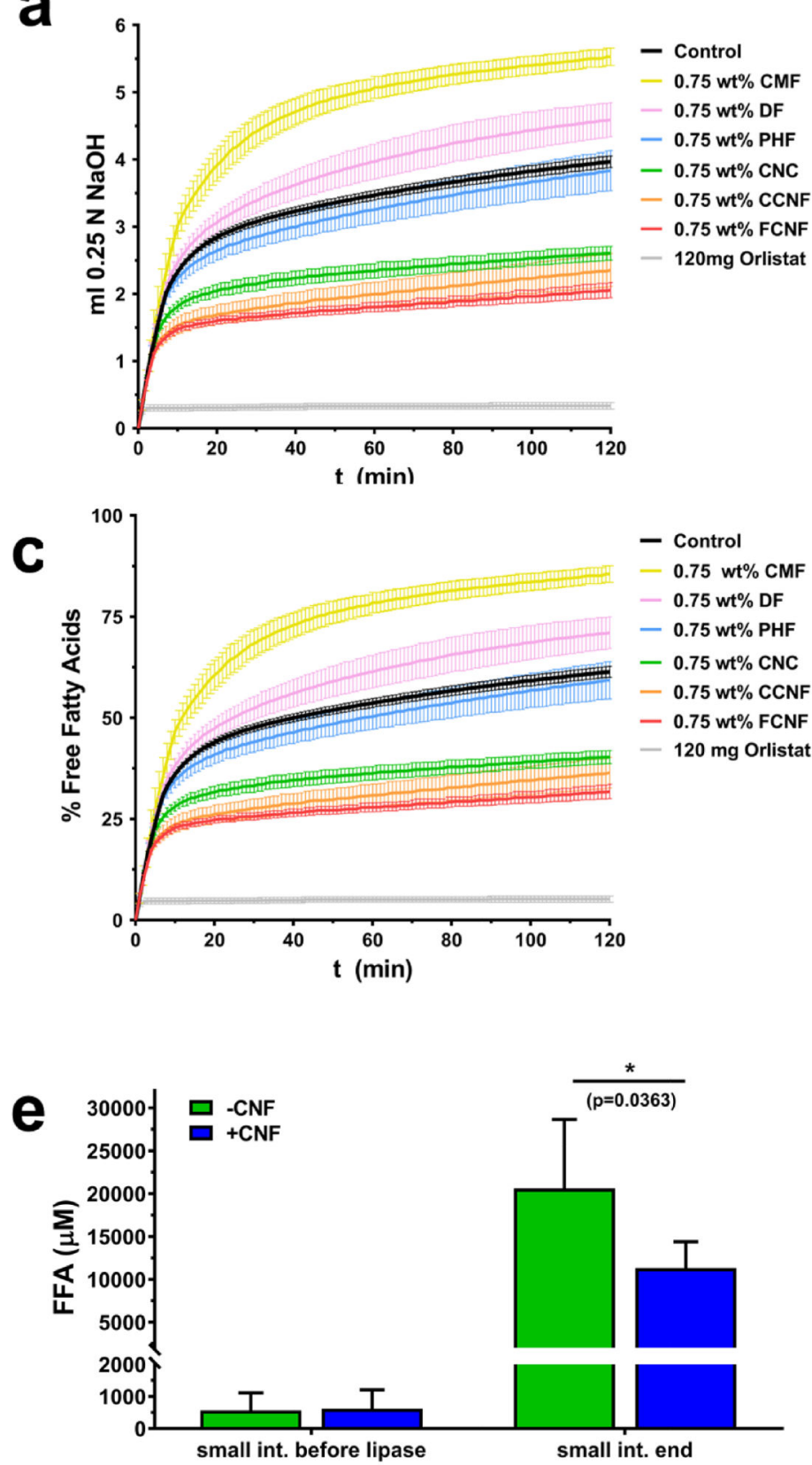

b

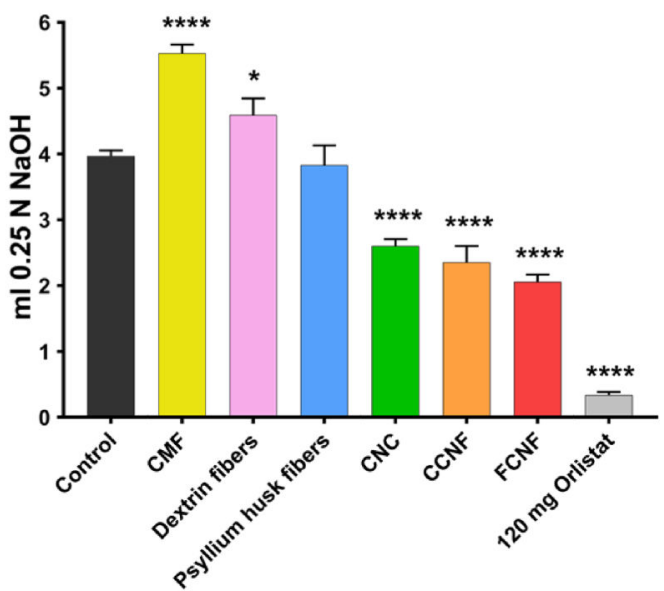

Figure 1 . Effect of cellulose and other fibers on in vitro triglyceride digestion:

a. $0.25 \mathrm{M} \mathrm{NaOH}$ titrant used to maintain digestae at $\mathrm{pH}=7.0$ during small intestinal digestion of heavy cream (initial $13.3 \% \mathrm{w} / \mathrm{w}$ fat food model) over time $(\mathrm{N}=3$ for orlistat and fibers, $\mathrm{N}=14$ for control). $\mathbf{b}$. total titrant used during small intestinal digestion of heavy cream. c. Percent of total available FFA released as a function of time during small intestinal 2 digestion of heavy cream. d. total percentage of FFA released during small intestinal digestion of heavy cream. e. FFA measured by fluorometric assay at beginning and end of small intestinal digestion of heavy cream with and without $0.75 \% 50 \mathrm{~nm} \mathrm{CNF}(\mathrm{N}=3)$. f. total 
percentage of FFA released during small intestinal digestion of different fatty food models (all at initial $13.3 \% \mathrm{w} / \mathrm{w}$ fat) with and without $0.75 \% 50 \mathrm{~nm} \mathrm{CNF} \mathrm{(N=3).} \mathrm{CMF:} \mathrm{micron} \mathrm{scale}$ cellulose fibrils, DF: wheat dextrin fibers, PHF: Psyllium husk fibers, CNC: cellulose nanocrystals, CCNF: $80 \mathrm{~nm} \mathrm{CNF,} \mathrm{FCNF:} 50 \mathrm{~nm} \mathrm{CNF}$. Error bars represent \pm SD, * $=\mathrm{p}<0.05$, $* * *=\mathrm{p}<.001, * * * *=\mathrm{p}<0.0001$. 


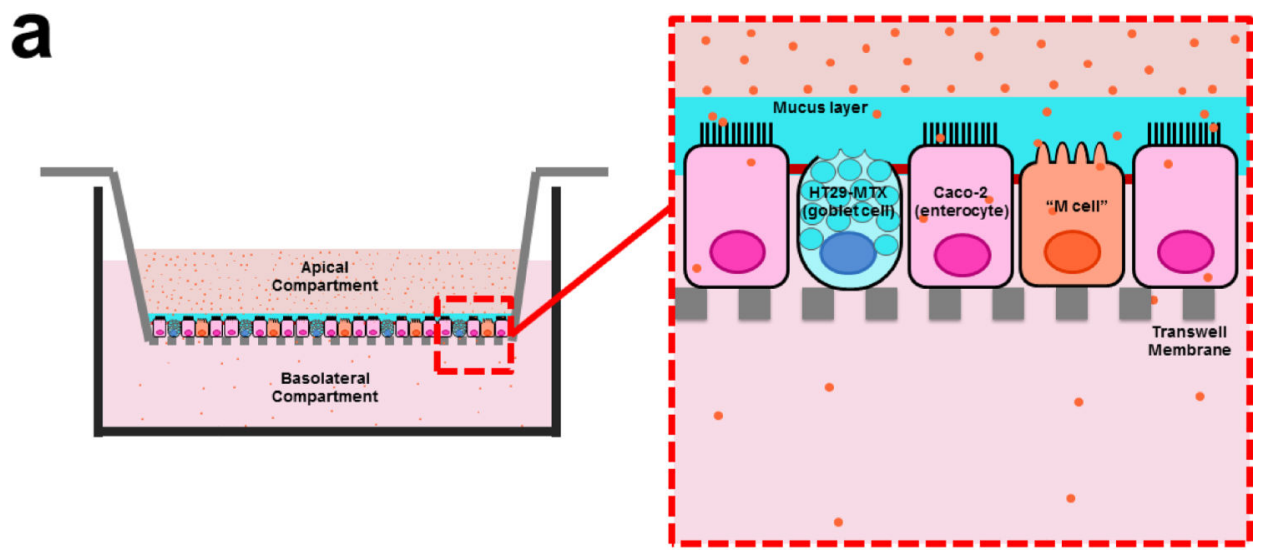

b

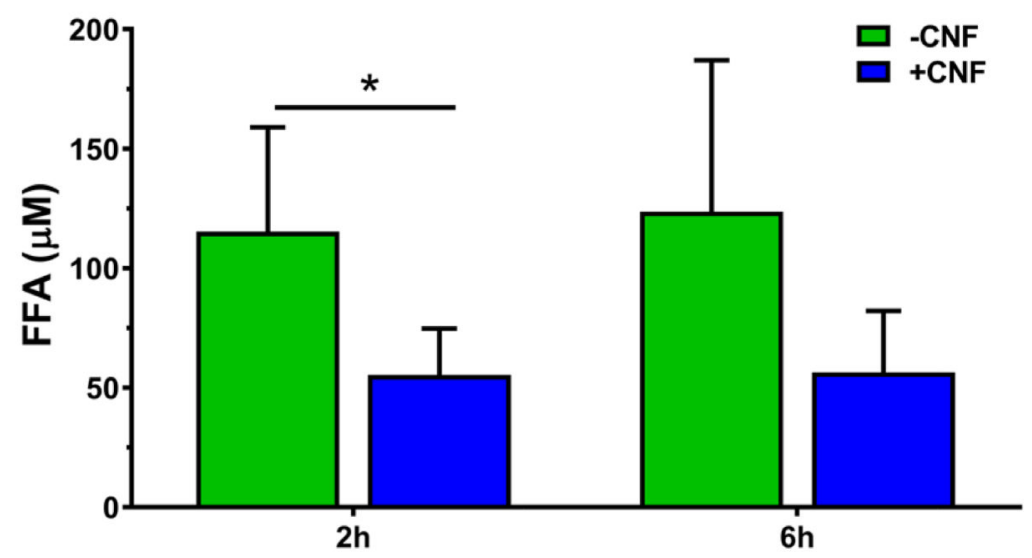

C

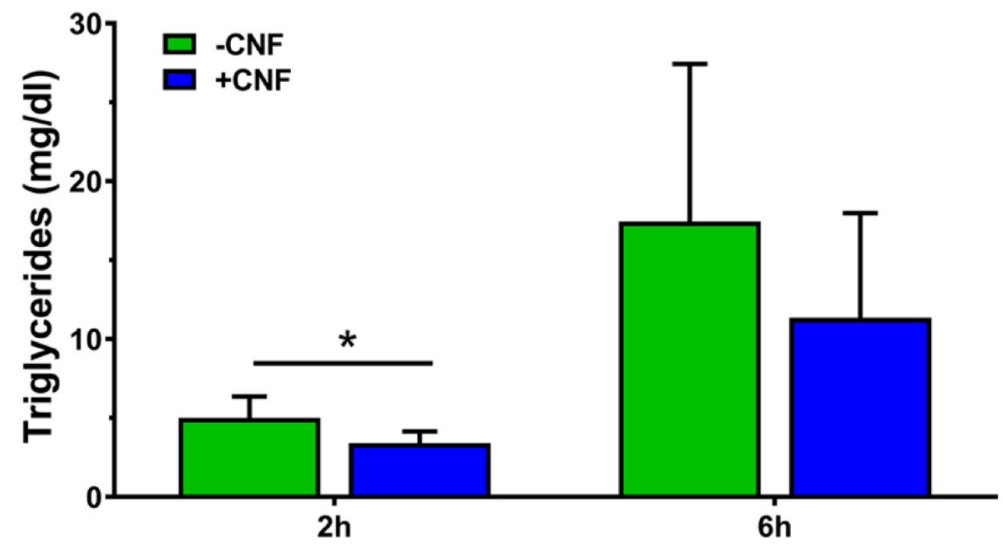

Figure 2 |. Effect of nanocellulose on biokinetics of FFA and TG in a triculture model:

a. Schematic of biokinetics experimental system. Intestinal epithelium triculture model was grown on transwell inserts. Digestae from simulated GIT digestion of heavy cream model ( $13.3 \%$ fat) with or with out $0.75 \% 50 \mathrm{~nm} \mathrm{CNF}$, was applied to the apical surfaces of the transwell inserts. b. FFA measured in basolateral compartments of triculture intestinal epithelial model at 2 and 6 hours after application of digesta from heavy cream with and without $\mathrm{CNF}(\mathrm{N}=3)$. c. TG measured in basolateral compartments of triculture intestinal 
epithelial model at 2 and 6 hours after application of digesta from heavy cream with and without $\mathrm{CNF}(\mathrm{N}=3)$. Error bars represent $\pm \mathrm{SD}, *=\mathrm{p}<0.05$. 


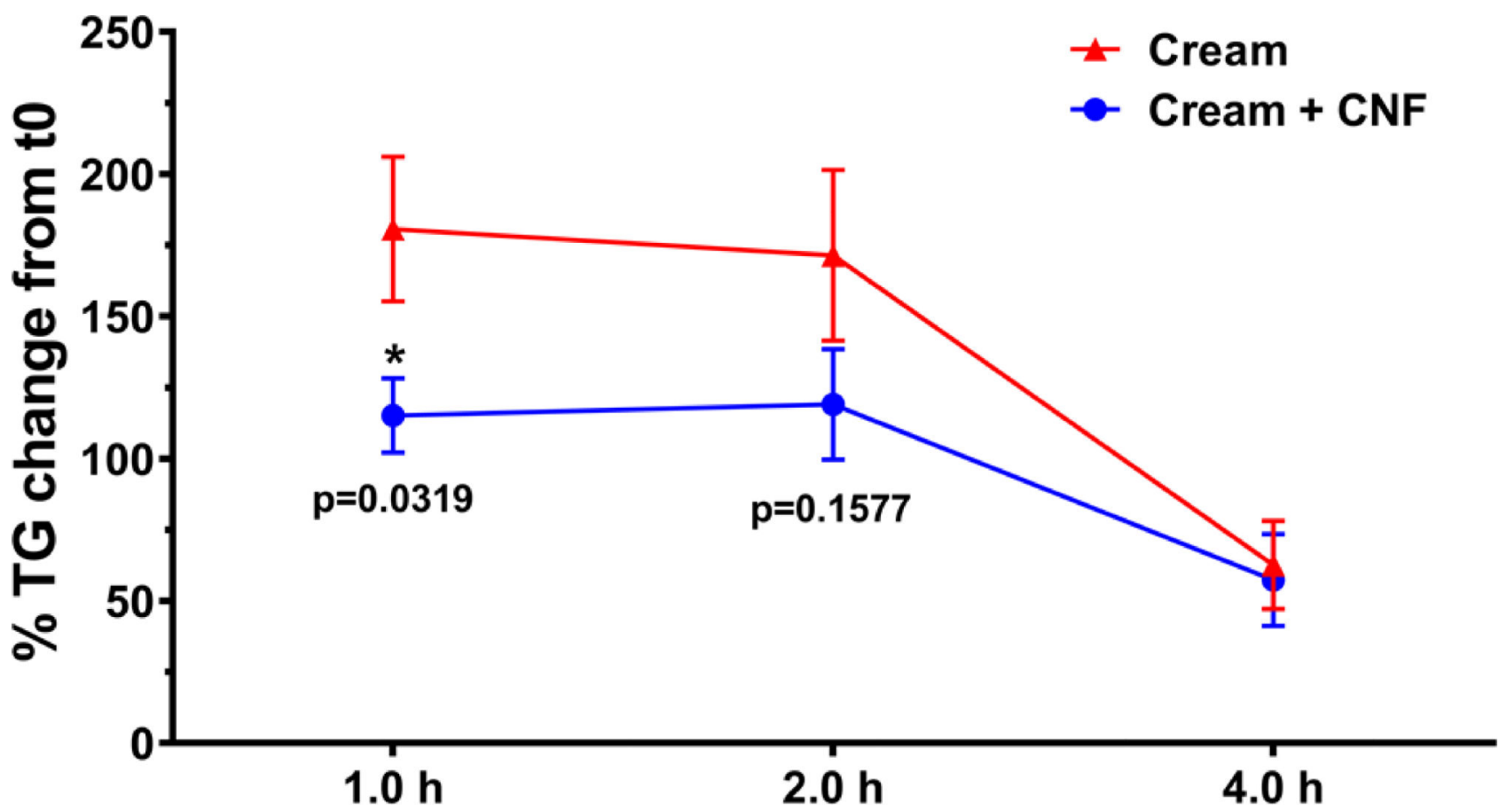

Figure 3 |. Effect of nanocellulose on change in rat serum TG after heavy cream gavage: Mean change in serum TG relative to baseline at 1,2 and $4 \mathrm{~h}$ in rats gavaged with $3 \mathrm{ml}$ heavy cream with or without $1 \% \mathrm{CNF}-50 . \mathrm{N}=12$ animals per group. 

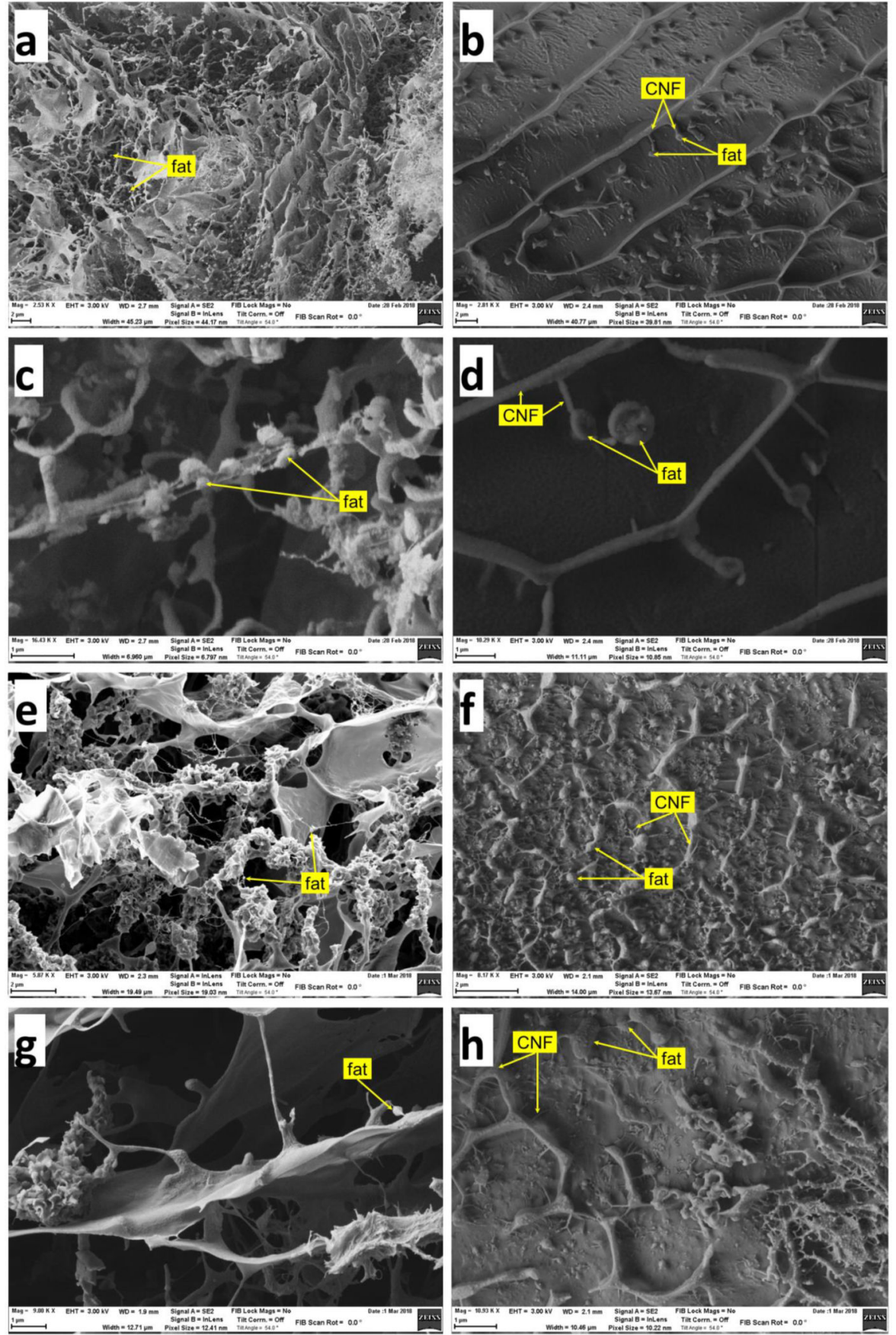

Figure 4 |. SEM images of digestae:

a. and c. digestae of cream only (13.3\%) at start of small intestinal phase (prior to addition of lipase). b. and d. digestae of cream (13.3\%) plus $0.75 \%$ CNF-50 at start of small intestinal phase. e. and g. digestae of cream only at end of small intestinal phase. $\mathbf{f}$. and $\mathbf{h}$. digestae of cream plus CNF at end of small intestinal digestion. 

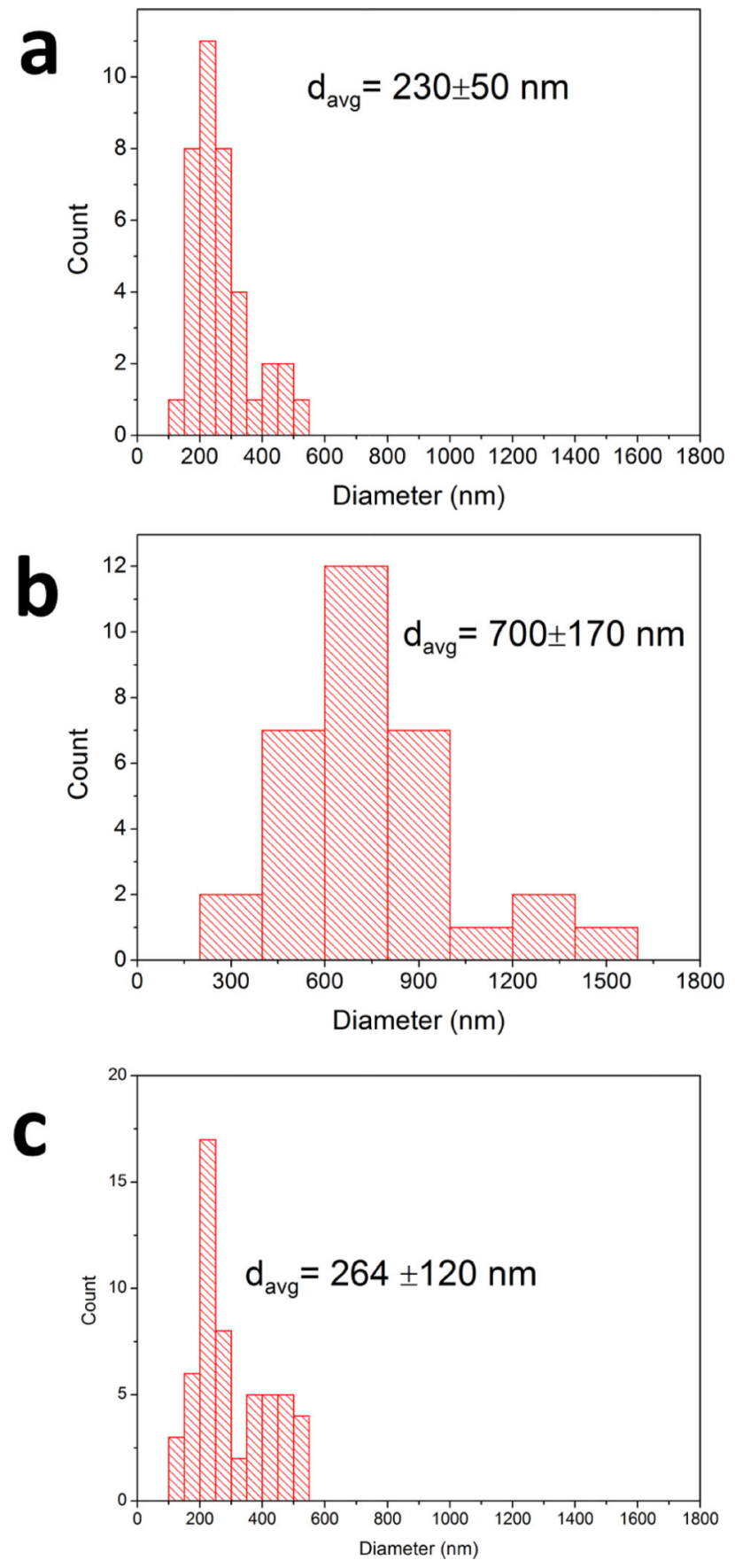

Figure 5 |. Fat droplet size distributions from SEM images:

Fat droplets were measured from SEM images representing digestae with and without CNF before lipase digestion and digesta with CNF following lipase digestion. a. distribution of fat droplet sizes in cream only samples prior to digestion ( $\mathrm{N}=38$ droplets analyzed). $\mathbf{b}$.

distribution in cream $+\mathrm{CNF}-50 \mathrm{~nm}$ prior to digestion $(\mathrm{N}=32)$. c. distribution in cream + CNF-50 nm following digestion for 2 hours $(\mathrm{N}=55)$. 
Table 1.

Binding energies from molecular dynamics simulations on cellulose nanofibers for each simulated system

\begin{tabular}{lc}
\hline \multicolumn{1}{c}{ System } & $\begin{array}{c}\text { Cellulose Fiber } \\
\text { Binding Energy (kcal/mol) } \pm \text { SD }\end{array}$ \\
\hline Palmitic Acid & $-2.2 \pm 2.3$ \\
Palmitic Triglyceride & $-4.4 \pm 2.5$ \\
Glycodeoxycholate & $-2.1 \pm 0.7$ \\
\hline
\end{tabular}

